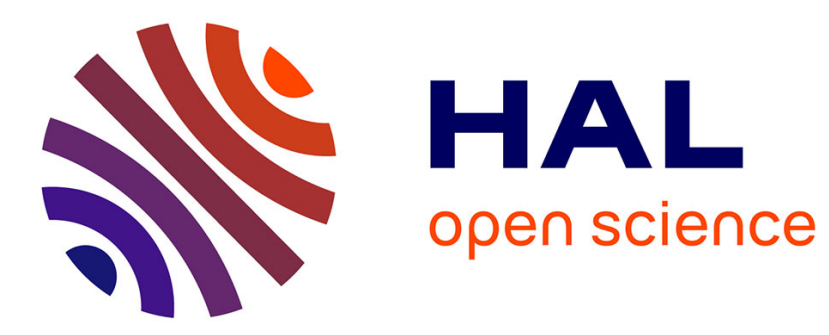

\title{
Brushless Three-Phase Synchronous Generator Under Rotating Diode Failure Conditions
}

Mohamed Salah, Khmais Bacha, Abdelkader Chaari, Mohamed Benbouzid

\section{To cite this version:}

Mohamed Salah, Khmais Bacha, Abdelkader Chaari, Mohamed Benbouzid. Brushless Three-Phase Synchronous Generator Under Rotating Diode Failure Conditions. IEEE Transactions on Energy Conversion, 2014, 29 (3), pp.594-601. hal-01063655

\section{HAL Id: hal-01063655 https://hal.science/hal-01063655}

Submitted on 12 Sep 2014

HAL is a multi-disciplinary open access archive for the deposit and dissemination of scientific research documents, whether they are published or not. The documents may come from teaching and research institutions in France or abroad, or from public or private research centers.
L'archive ouverte pluridisciplinaire HAL, est destinée au dépôt et à la diffusion de documents scientifiques de niveau recherche, publiés ou non, émanant des établissements d'enseignement et de recherche français ou étrangers, des laboratoires publics ou privés. 


\title{
Brushless Three-Phase Synchronous Generator under Rotating Diode Failure Conditions
}

\author{
Mohamed Salah, Khmais Bacha, Abdelkader Chaari, and Mohamed Benbouzid, Senior Member, IEEE
}

\begin{abstract}
In brushless excitation systems, the rotating diodes can experience open- or short-circuits. For a three-phase synchronous generator under no-load, we present theoretical development of effects of diode failures on machine output voltage. Thereby, we expect the spectral response faced with each fault condition, and we propose an original algorithm for state monitoring of rotating diodes. Moreover, given experimental observations of the spectral behavior of stray flux, we propose an alternative technique. Laboratory tests have proven the effectiveness of the proposed methods for detection of fault diodes, even when the generator has been fully loaded. However, their ability to distinguish between cases of diodes interrupted and short-circuited, has been limited to the no-load condition, and certain loads of specific natures.
\end{abstract}

Index Terms--Alternators, brushless machines, fault detection, fault diagnosis, monitoring, spectral analysis.

\section{NOMENCLATURE}

$\alpha$ Instantaneous angle of the rectifier input voltage;

$A_{n} \quad n$th Fourier series coefficient;

$\beta \quad$ Additional phase shifting due to short-circuit condition;

$e_{a} \quad$ emf induced in stator phase $a$ under no-load condition;

$E_{1 ; 1}^{ \pm}$Normalized amplitude of the frequency $\omega_{1 ; 1}^{ \pm}$;

$E_{v}$ Maximal amplitude related to the $v$ th harmonic of $e_{a}$;

$\mathrm{H}_{\mathrm{n}} \quad n$th harmonic of fundamental frequency $\omega_{\mathrm{m}}$;

$i_{f} \quad$ Instantaneous excitation coil current;

$I_{f}$ dc component of the excitation coil current;

$K \quad$ Ratio of characteristic defect frequencies $\omega_{1 ; 1}^{ \pm}$;

$L \quad$ Inductance of the excitation coil;

$M_{a}^{f}$ Mutual inductance linking excitation coil and phase $a$;

$M_{v}$ Maximal amplitude related to the $v$ th harmonic of $M_{a}^{f}$;

$\Omega \quad$ Mechanical speed;

$\omega_{\mathrm{e}}$ Fundamental frequency of the rectifier input voltage;

$\omega_{H}^{ \pm}$Prevailing sideband components under intact bridge;

$\omega_{i ; v}^{ \pm}$Sideband frequencies;

M. Salah, K. Bacha, and A. Chaari are with the Unit of Research in Control, Monitoring and Reliability of the Systems, University of Tunis, Higher School of Sciences and Techniques of Tunis, Taha Hussein Street 1008 Tunis, Tunisia (e-mail: mohamed.salah.isetgf@gmail.com; khmaisbacha@voila.fr; nabile.chaari@yahoo.fr).

M.E.H. Benbouzid is with the University of Brest, EA 4325 LBMS, Brest, France (e-mail: Mohamed.Benbouzid@univ-brest.fr). $\omega_{\mathrm{m}}$ Fundamental frequency of the main output voltage;

$p_{e} \quad$ Number of pair-poles related to the exciter;

$p_{m}$ Number of pair-poles related to the main generator;

$\varphi_{f}^{n} \quad$ Phase shifting related to the $n$th excitation coil current;

$\psi_{a}$ Permanent flux embraced by stator phase $a$;

$R \quad$ Resistance of the excitation coil;

$\rho_{i ; v}^{ \pm}$Maximal amplitude related to the frequency $\omega_{i, v}^{ \pm}$;

$\mathrm{U}$ Maximal line to line input voltage of the rectifier bridge;

$u_{f}$ Instantaneous output voltage of the rectifier bridge;

$v_{j} \quad j$ th rectifier input voltage;

$\xi \quad$ Amplitudes ratio related to sidebands $\omega_{1 ; 1}^{ \pm}$.

\section{INTRODUCTION}

$\mathrm{M}$ ost systems of electrical energy production are based on three-phases synchronous generators. According to their excitation technique, these generators can be classified into brushed and brushless machines.

A brushless excitation system is provided by an auxiliary synchronous generator (exciter) mechanically coupled to the end of the main alternator's shaft. This exciter is with stationary field coils and rotating armature. A diodes bridge, mounted on a plate attached to the rotor, allows rectifying the ac input voltage of its armature. Therefore, the excitation coil of the main generator will be fed by a dc field current. By means of an automatic voltage regulator (AVR), the exciter field current is auto-adjusted for regulating the generator's output voltage level, faced to load variations (Fig. 1).

Due to ageing phenomenon and to process's continuous regime, rectifier diodes can fail either open- or short-circuit (Fig. 2).

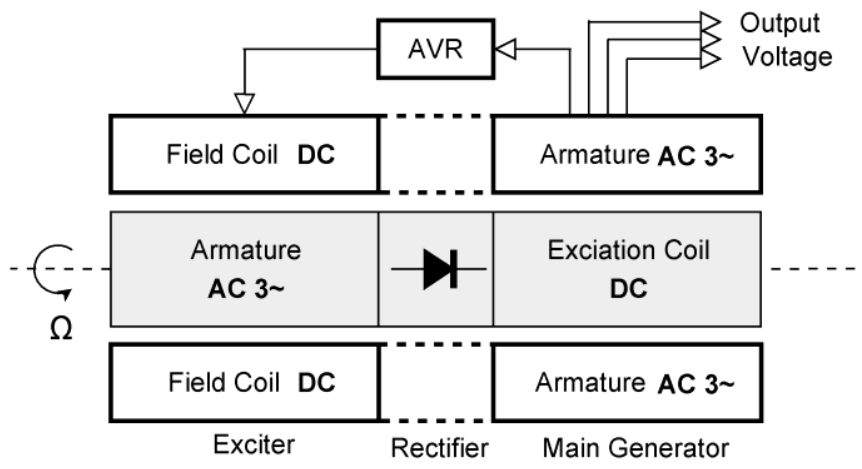

Fig. 1. Typical architecture of brushless synchronous generators. 


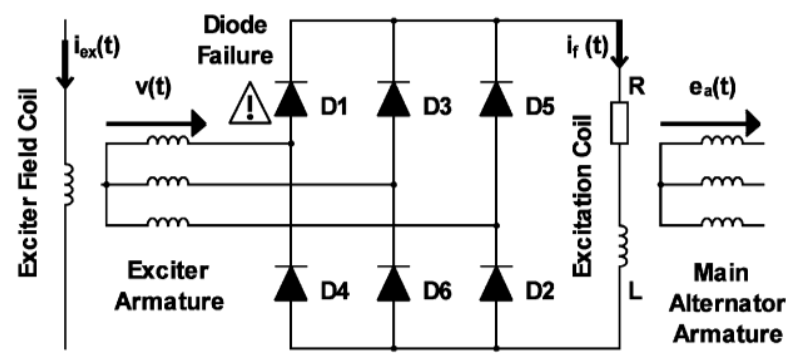

Fig. 2. Rotating Diodes bridge.

While under interrupted diode condition (ID), the alternator can operate safely with limited transient capability, subjected to condition of short-circuited diode (SD), the exciter becomes extremely overloaded and the alternator can no longer run securely. If such condition is prolonged, the AVR as well as the exciter windings can be damaged [1].

For a long time, the development of appropriate approaches for early detection of diode faults was a task of interesting research for the scientific community. The main idea was based on the implementation of a search coil into the exciter stator slots. Through spectral analysis of the induced electromotive force (EMF), many authors [2] have proposed the amplitudes monitoring of the second and of the sixth harmonics. Unfortunately, most of the synchronous generators are not already equipped with an incorporated search coil. In addition, the integration of such sensor into an existing stator winding arrangement is not always practical. To overcome this drawback, other works were focused on the harmonic analysis of the exciter field current. The main proposed indicators have dealt on ratio monitoring of the fundamental component regarding the dc level [1], as well as on the amplitude oversight of the component related to twice rated frequency [3]. In [4], others authors have suggested to measure the brushless transfer characteristic, given by the ratio of the generator's output voltage and the exciter field current.

On the other hand, many diagnosis techniques based on machine's models [5], [6], [7], [8] and control algorithms [9], [10] have been suggested. Recently, via voltage-behindreactance formulation of the stator and the field windings, the model proposed in [11] has proven its applicability in an excitation failure case study.

On the basis of spectral analysis of the generator output voltage, we are going to suggest an original algorithm for monitoring the state of rotating diodes. An alternative based on the stray flux will be also proposed. The efficiency of both techniques will be experimentally discussed according to the load condition.

\section{FAULTS EFFECTS ON THE GENERATOR'S INDUCED EMF}

In the following study, the machine under investigation is no-loaded, and is driven at its rated speed $\Omega$. Thereby, there is no magnetic interaction between the generator's stator coils.

For simplification purpose, we neglect the saturation phenomena and coil-damping effects. The rectifier bridge is supposed to be supplied by balanced voltages given by

$$
v_{j}(\alpha)=(\mathrm{U} / \sqrt{3}) \cdot \sin [\alpha-2 \pi(j-1) / 3], \quad j=1,2,3
$$

where

$$
\alpha=\omega_{e} t, \omega_{e}=p_{e} \Omega .
$$

In addition, we suppose that all diodes' switching is ideal. The current's transfer from one diode to another will be assumed to be instantaneous.

\section{A. Case of Intact Bridge}

Due to the bridge's symmetrical structure, rectified voltage $u_{f}$ is a dc component with tiny ac ripple (six pulses during each input voltage cycle).

For $\pi / 6 \leq \alpha \leq \pi / 2$, the expression of $u_{f}$ will be given by

$$
u_{f}(\alpha)=\mathrm{U} \cdot \cos (\alpha-\pi / 3) .
$$

To compute the expression of the excitation coil current, we expand $u_{f}$ into Fourier series. By taking into account the effects of the impedance $(R, L)$, we can write

$$
i_{f}(\alpha)=I_{f}\left[1+\sum_{k=1}^{\infty}(-1)^{k} A_{6 k} \cdot \cos (6 k \alpha)\right]
$$

where $I_{f}=3 \mathrm{U} /(\pi R), \tan \left(\varphi_{f}^{k}\right)=k \cdot L \omega_{e} / R$, and

$$
A_{6 k}=\frac{-2}{36 k^{2}-1} \cos \left(\varphi_{f}^{6 k}\right) .
$$

Because $k . L \omega_{e}>>R$, we can write

$$
\cos \left(\varphi_{f}^{k}\right) \approx \cos \left(\varphi_{f}^{1}\right) / k .
$$

Thereby, (5) gives

$$
A_{6 k}=\frac{-1}{3 k\left(36 k^{2}-1\right)} \cos \left(\varphi_{f}^{1}\right) .
$$

On the other hand, the flux embraced by the stator coil $a$ is given by

$$
\psi_{a}(t)=M_{a}^{f}(t) \cdot i_{f}(t) .
$$

Due to discrete character of stator winding distribution, the mutual inductance in (8) may be expressed by

$$
M_{a}^{f}(t)=\sum_{v=1}^{+\infty} M_{v} \cdot \cos \left(v \omega_{m} t\right), \quad v=1,3,5 \ldots
$$

where

$$
\omega_{m}=p_{m} \Omega .
$$

Time derivation of (8) using (4) and (9) gives

$$
e_{a}(t)=\sum_{v=1}^{+\infty} E_{v} \cdot\left[\sin \left(v \omega_{m} t\right)+\sum_{k=1}^{\infty}(-1)^{k} \rho_{6 k ; v}^{ \pm} \cdot \sin \left(\omega_{6 k ; v}^{ \pm} t\right)\right]
$$

where $E_{v}=v p_{m} \Omega I_{f} M_{v}$, and

$$
\begin{aligned}
\rho_{i ; v}^{ \pm} & =\frac{1}{2}\left(\frac{i \cdot p_{e}}{v \cdot p_{m}} \pm 1\right) A_{i}, \\
\omega_{i ; v}^{ \pm} & =\left(i \cdot p_{e} \pm v \cdot p_{m}\right) \Omega .
\end{aligned}
$$

As shown by the previous equation, besides the fundamental frequency $\omega_{\mathrm{m}}$ and its odd harmonics, the EMF spectrum includes other sidebands $\omega_{6 k ; \nu}^{ \pm}$. The prevailing components are obtained for $k=v=1$ :

$$
\omega_{H}^{ \pm}=6 . \omega_{e} \pm \omega_{\mathrm{m}} .
$$

For $\omega<6 \omega_{e}-\omega_{\mathrm{m}}$, sidebands $\omega_{H}^{ \pm}$cannot be observed. 


\section{B. Case of Interrupted Diode}

Under such fault condition, the rectified voltage waveform is cyclic with main frequency $\omega_{e}$ (Fig. 3). Its analytical expressions are reported in Table I.

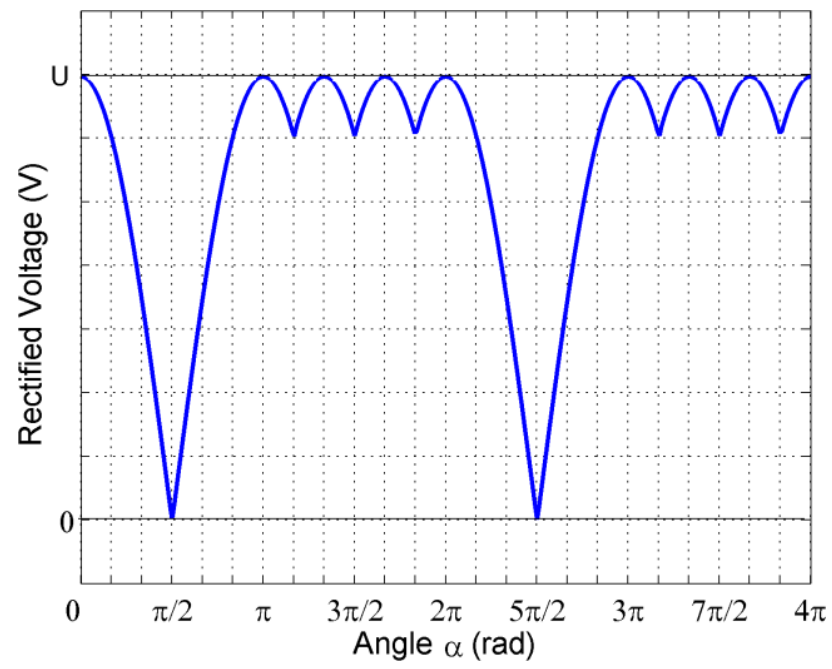

Fig. 3. Rectified voltage under ID condition.

TABLE I

Expressions of the rectified voltage under ID condition

\begin{tabular}{cc|cc}
\hline \hline Intervals & Expression & Interval & Expression \\
\hline $0 \leq \alpha \leq \frac{\pi}{2} ; \frac{11 \pi}{6} \leq \alpha \leq 2 \pi$ & $\mathrm{U} \cos (\alpha)$ & $\frac{7 \pi}{6} \leq \alpha \leq \frac{3 \pi}{2}$ & $\mathrm{U} \cos \left(\alpha+\frac{2 \pi}{3}\right)$ \\
$\frac{\pi}{2} \leq \alpha \leq \frac{7 \pi}{6}$ & $-\mathrm{U} \cos (\alpha)$ & $\frac{3 \pi}{2} \leq \alpha \leq \frac{11 \pi}{6}$ & $\mathrm{U} \cos \left(\alpha+\frac{\pi}{3}\right)$ \\
\hline \hline
\end{tabular}

By following a similar reasoning as of subsection III.A, we can deduce the expression of the excitation coil current:

$$
\left.i_{f}^{I D}(\alpha)=\frac{5 I_{f}}{6} \mid \begin{array}{l}
1+\sum_{k=0}^{\infty}(-1)^{k+1} A_{2 k+1}^{I D} \sin ((2 k+1) \alpha) \\
+\sum_{k=1}^{\infty}(-1)^{k} A_{2 k}^{I D} \cos (2 k \alpha)
\end{array}\right]
$$

where

$$
\mid \begin{aligned}
& A_{1}^{I D}=\frac{-\pi}{5 \sqrt{3}} \cos \left(\varphi_{f}^{1}\right) \\
& A_{n \neq 1}^{I D}=-2 \frac{2 \cos (2 n \pi / 3)+(-1)^{n}+2}{5 n\left(n^{2}-1\right)} \cos \left(\varphi_{f}^{1}\right)
\end{aligned} .
$$

Thus, the expression of the induced EMF becomes

$$
e_{a}^{I D}(t)=\frac{5}{6} \sum_{v=1}^{+\infty} E_{v}\left[\begin{array}{l}
\sin \left(v \omega_{m} t\right)+\sum_{k=1}^{\infty}(-1)^{k} \rho_{2 k ; v}^{I D \pm} \sin \left(\omega_{2 k ; v}^{ \pm} t\right) \\
+\sum_{k=0}^{\infty}(-1)^{k} \rho_{2 k+1 ; v}^{I D \pm} \cos \left(\omega_{2 k+1 ; v}^{ \pm} t\right)
\end{array}\right] .
$$

This previous equation shows that ID condition involves an amplitude modulation of the induced EMF's wave.

For $k=0, v=1$, and $\omega<6 \omega_{e}-\omega_{\mathrm{m}}$, the outstanding sideband frequencies characterizing the fault occurrence are given by

$$
\omega_{1 ; 1}^{ \pm}=\left(p_{e} \pm p_{m}\right) \Omega \text {. }
$$

\section{Case of Short-circuited Diode}

Fig. 4 shows the rectified voltage related to the SD condition. Its waveform consists of a transient component which disappears when $\alpha=4 \pi / 3$, followed by a permanent cyclic wave with main frequency $\omega_{e}$ (Table II).

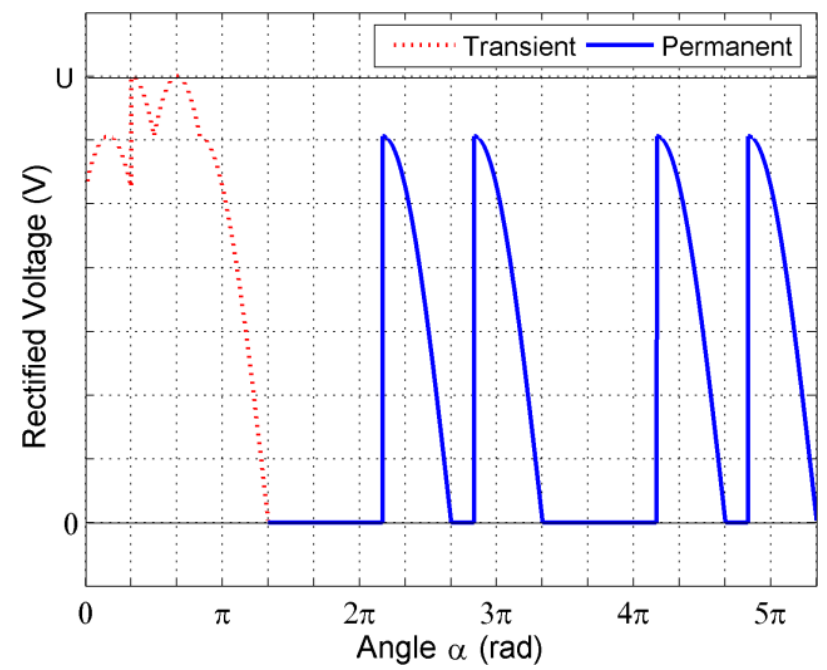

Fig. 4. Rectified voltage under SD condition.

TABLE II

Expressions of the rectified voltage under SD condition

\begin{tabular}{cc|cc}
\hline \hline \multicolumn{2}{c|}{ Transient component } & \multicolumn{2}{c}{ Cyclic permanent component } \\
Interval & Expression & Expression \\
\hline $0 \leq \alpha<\frac{\pi}{3}$ & $\frac{\sqrt{3}}{2} \mathrm{U} \cos \left(\alpha-\frac{\pi}{6}\right)$ & $\frac{4 \pi}{3} \leq \alpha<\frac{13 \pi}{6}$ & 0 \\
$\frac{\pi}{3} \leq \alpha \leq \frac{\pi}{2}$ & $\mathrm{U} \cos \left(\alpha-\frac{\pi}{3}\right)$ & $\frac{13 \pi}{6} \leq \alpha \leq \frac{8 \pi}{3}$ & $\frac{\sqrt{3}}{2} \mathrm{U} \cos \left(\alpha-\frac{\pi}{6}\right)$ \\
$\frac{\pi}{2} \leq \alpha \leq \frac{5 \pi}{6}$ & $\mathrm{U} \cos \left(\alpha-\frac{2 \pi}{3}\right)$ & $\frac{8 \pi}{3} \leq \alpha<\frac{17 \pi}{6}$ & 0 \\
$\frac{5 \pi}{6} \leq \alpha \leq \frac{4 \pi}{3}$ & $\frac{\sqrt{3}}{2} \mathrm{U} \cos \left(\alpha-\frac{5 \pi}{6}\right)$ & $\frac{17 \pi}{6} \leq \alpha \leq \frac{10 \pi}{3}$ & $-\frac{\sqrt{3}}{2} \mathrm{U} \cos \left(\alpha+\frac{\pi}{6}\right)$ \\
\hline \hline
\end{tabular}

Fourier transformation of the transient component gives

$$
\overline{U_{f}^{S D}}(\omega)=-\frac{\mathrm{U}}{48 \omega}[(5 \pi+3 \sqrt{3})+(11 \sqrt{3} \pi+21) j] .
$$

Far from the moment of the fault occurrence, the excitation coil is supplied by the cyclic component. Fourier series expansion gives

$$
i_{f}^{s D}(\alpha)=\frac{I_{f}}{2 \sqrt{3}}\left[\begin{array}{l}
1+A_{1}^{s d} \cos \left(\alpha+\beta_{1}\right) \\
+\sum_{k=1}^{\infty}\left[A_{2 k}^{s d} \cos \left(2 k \alpha+\beta_{2 k}\right)\right] \\
+\sum_{k=1}^{\infty}\left[A_{2 k+1}^{s d} \cos ((2 k+1) \alpha)\right]
\end{array} \mid\right.
$$

where

$$
\tan \left(\beta_{1}\right)=\pi / 2, \quad \tan \left(\beta_{2 k}\right)=2 k(-1)^{k},
$$

and 


$$
\mid \begin{aligned}
& A_{1}^{S D}=\frac{-\sqrt{\pi^{2}+4}}{4} \cos \left(\varphi_{\mathrm{f}}^{1}\right) \\
& A_{2 k}^{S D}=\frac{-\sqrt{1+4 k^{2}}}{k\left(4 k^{2}-1\right)} \cos \left(\frac{k \pi}{3}\right) \cos \left(\varphi_{\mathrm{f}}^{1}\right) \\
& A_{2 k+1}^{S D}=\frac{-\left[2 k-(-1)^{k}+1\right] \cos \left(\frac{(k-1) \pi}{3}\right)}{2 k(k+1)(2 \mathrm{k}+1)} \cos \left(\varphi_{\mathrm{f}}^{1}\right)
\end{aligned} .
$$

Accordingly, the expression of the induced EMF becomes

$$
e_{a}^{S D}(t)=\frac{1}{2 \sqrt{3}} \sum_{v=1}^{+\infty} E_{v} \cdot\left[\begin{array}{c}
\sin (v \omega t)+\rho_{1 ; \nu}^{S D \pm} \sin \left(\omega_{1 ; \nu}^{ \pm} t+\beta_{1}\right) \\
+\sum_{k=1}^{\infty}\left[\rho_{2 k ; v}^{S D \pm} \sin \left(\omega_{2 k ; v}^{ \pm} t+\beta_{2 k}\right)\right] \\
+\sum_{k=1}^{\infty}\left[\rho_{2 k+1 ; v}^{S D \pm} \sin \left(\omega_{2 k+1 ; v}^{ \pm} t\right)\right]
\end{array}\right] \cdot
$$

As shown by (17) and (23), both diode failure cases have the same frequency signature. Thus, the distinguishing between fault conditions (ID or SD) remains ambiguous.

\section{Distinguishing Between Fault Conditions}

For both cases of diode failures, the rise in amplitude of characteristic sidebands $\omega_{1 ; 1}^{ \pm}$, derives from the presence of frequencies $\omega_{k ; v}^{ \pm}$with $k=v=1$, and all other components $\left|\omega_{k ; v}^{-}\right|$such that $k=2 \lambda p_{m}+1$ and $v=2 \lambda p_{e} \mp 1$, or $k=2 \lambda p_{m}-1$ and $v=2 \lambda p_{e} \pm 1$, where $\lambda=1,2,3 \ldots$

Accordingly to (17) and to (23), by disregarding all effects due to $(k, v) \neq(1,1)$ we can expect that the normalized amplitudes of sidebands $\omega_{1 ; 1}^{ \pm}$will be given by

$$
E_{1 ; 1}^{I D \pm}=\frac{\left(p_{e} \pm p_{m}\right)}{2 p_{m}}, E_{1 ; 1}^{S D \pm}=\frac{\left(p_{e} \pm p_{m}\right)}{2 \pi p_{m}} \sqrt{\pi^{2}+4} .
$$

Previous expression shows that these amplitudes are slightly more accentuated in case of SD $\left(E_{1 ; 1}^{S D \pm}-E_{1 ; 1}^{I D \pm} \approx 1.5 \mathrm{~dB}\right)$.

In addition, it seems that the amplitudes ratio defined by $\xi=E_{1 ; 1}^{+} / E_{1 ; 1}^{-}$is closely equal to the frequencies ratio $K=\omega_{1 ; 1}^{+} / \omega_{1 ; 1}^{-}$:

$$
\xi=K \text {. }
$$

However, due to fault conditions, the currents flowing into the exciter armature becomes unbalanced. It follows the emergence of a rotating zero-sequence component. Given that condition, the rotational speed $\Omega$ and its harmonics will be reflected into the EMF spectrum. Therefore, the expression given (25) cannot be strictly respected. The ratio $\xi$ will tend to be lesser than the ratio $K$.

While this unbalance effect remains relatively moderate for ID faults, it is very significant in case of faults of SD nature. Indeed, under SD condition, the unbalance level will be more intensified because of the exciter windings overload.

Given the previous statements, we can deduce that the amplitudes ratios $\left(\xi_{0}^{I D}\right.$, and $\left.\xi_{0}^{S D}\right)$ related to unloaded generator condition (UGC), and the frequencies ratio $K$ are bound by the comparison expression given by

$$
\xi_{0}^{S D}<<\xi_{0}^{I D}<K .
$$

Thus, the monitoring of the ratio $\xi_{0}$ range can be an efficient indicator to distinguish between open- and short-circuit diode failures.

By loading the generator under fault condition, the effect of the rotating zero-sequence component on the ratio $\xi$ will be certainly altered. Hence, the expression given by (26) can no longer be guaranteed especially in case of short circuit. This prediction will be verified experimentally for various load natures.

\section{USEFUlNESS OF THE MAGNETIC StRAy FluX}

From a design standpoint, electrical machines include two different circuits. Whereas the electric circuit (coils) ensures the currents flow, the magnetic circuit is the main pathway for channeling magnetic fluxes. The physical phenomena involving the two circuits' parameters are basically governed by electromagnetism laws. A circulating current through an electric circuit (field coils) produces a magnetic field (vector quantity). At different points in space, the properties of this vector are given by means of Biot-Savart law [13]. The measurement (inner vectors product) of the quantity of magnetic field that crosses perpendicularly an opened surface (electric circuit) gives rise to the magnetic flux which is a not null scalar. In accordance with Faraday's law, the time variation of this magnetic flux produces a boundary EMF (generator mode) tending to drive current through the concerned circuit (armature coils). On the other hand, in the presence of a magnetic field, a current-carrying wire endures a Laplace force (macroscopic form of Lorenz force). Consequently, an electromagnetic torque may be produced (motor mode).

Because of the inherent machine dissymmetry, the limited relative permeability of the magnetic circuit, and the effects of the air-gap length, a portion of the magnetic flux will radiate outside of the machine's frame. This stray flux does not participate in the process of generating of useful outputs. However it has the particularity to provide useful information about the phenomena that occur inside the machine. Indeed, when a fault occurs into stator or rotor windings, harmonics distribution into the air-gap will be altered. Consequently, the stray flux will certainly undergo these changes. A simple search coil placed near the machine's frame will retrieves an image of this stray flux (time derivative). Therefore, by spectral analysis of the EMF induced at the coil terminals, we can detect a possible failure in the machine circuits [14].

\section{EXPERIMENTAL RESULTS}

The brushless machine under investigation is a 4-kVA, 380$\mathrm{V}, 50-\mathrm{Hz}$, four-pole generator with 14-pole exciter.

For three diode conditions (intact bridge, ID, and SD), experimental tests have been conducted under UGC as well as under fully loaded generator condition (FGC), with various 
load natures. The output voltage, and EMF at coil terminals, were acquired at $25-\mathrm{kHz}$ sampling rate, and recorded for $10 \mathrm{~s}$ (Fig. 5). As predicted by the theoretical study, characteristic sidebands, and their ratio worth, respectively, $\omega_{1 ; 1}^{-}=125 \mathrm{~Hz}, \omega_{1 ; 1}^{+}=225 \mathrm{~Hz}$, and $K=1.8(5.1 \mathrm{~dB})$.

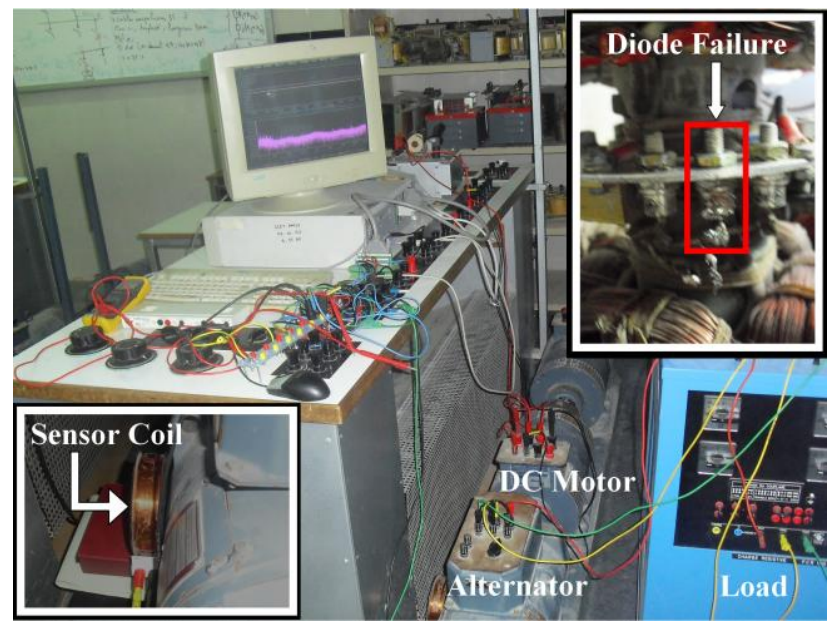

Fig. 5. Laboratory test bench.

\section{A. No-load Generator}

For the ID fault condition, an amplitude rise of sidebands $\omega_{1 ; 1}^{ \pm}$is clearly observed (Fig. 6), as expected by (17).

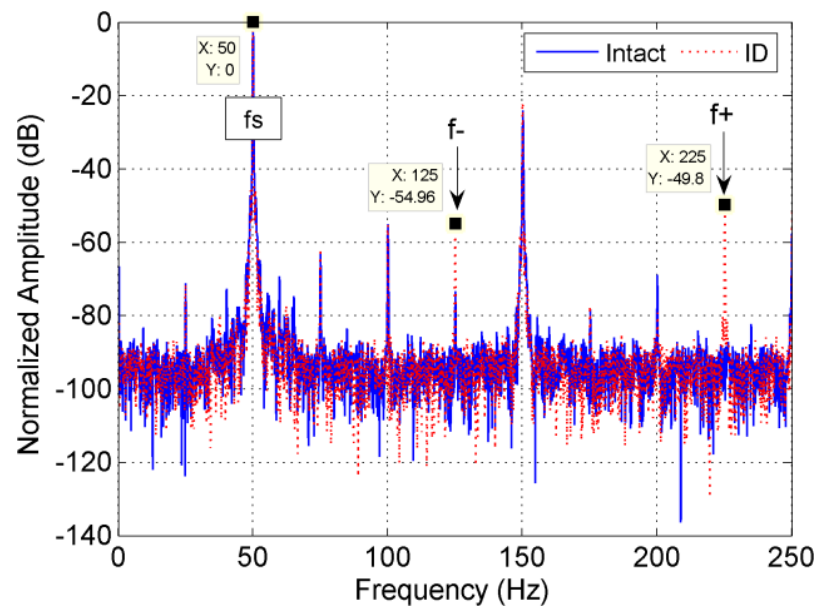

Fig. 6. Output voltage spectra: intact - ID for no-load generator.

This same spectral fault signature is also observed when the generator is running under SD condition (Fig. 7). However, due to the significant effect of the rotating zero-sequence component, this spectral response is marked by the presence of additional harmonics related to the rotational frequency. Moreover, whereas under ID condition the amplitudes ratio $\xi_{0}^{I D}$ is closely equal to the ratio $K\left(\xi_{0}^{I D}=5.16 \mathrm{~dB}\right)$, under SD condition this ratio falls to about half $\left(\xi_{0}^{S D}=-0.4 \mathrm{~dB} \approx 53 \% . K\right)$. These experimental results confirm the comparison expression given by (26).

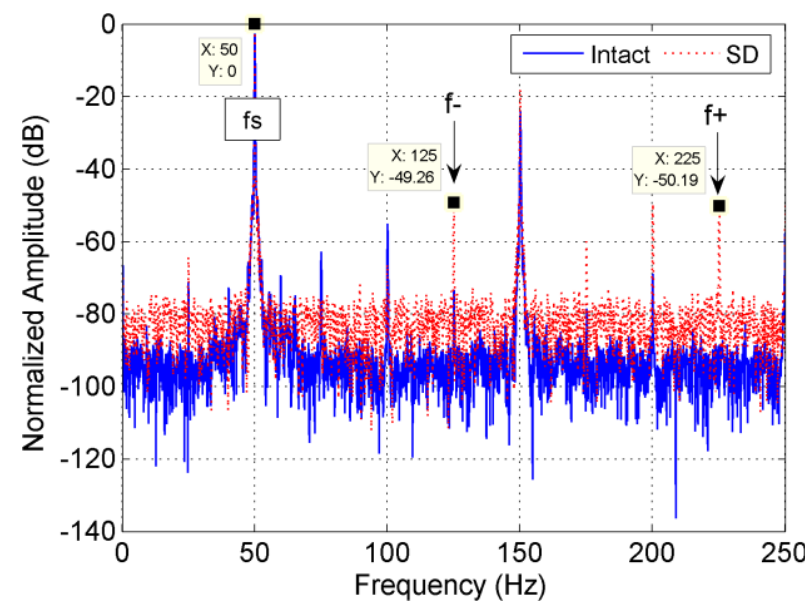

Fig. 7. Output voltage spectra: intact - SD for no-load generator.

On the other hand, the spectral responses of the stray flux to both diode failure cases are given in Fig. 8, and in Fig. 9.

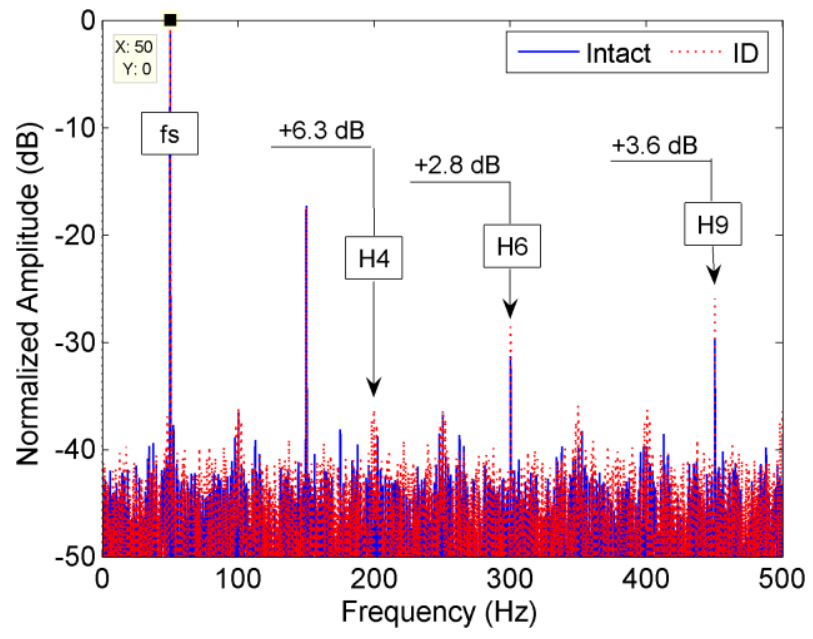

Fig. 8. Stray flux spectra: intact - ID for no-load generator.

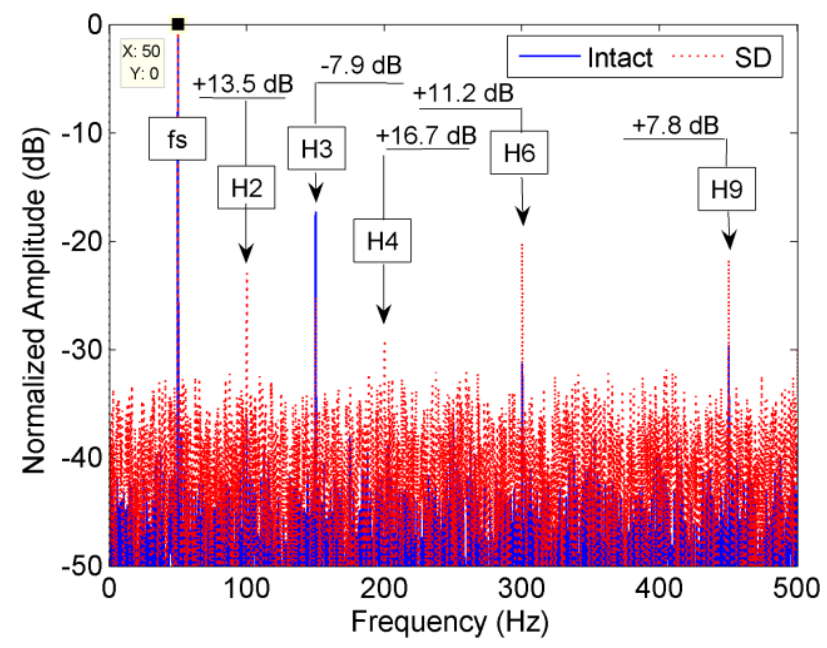

Fig. 9. Stray flux spectra: intact - SD for no-load generator.

For both conditions, these spectra are characterized by an amplitude rise, observed especially for the 4th, the 6th, and the 9th harmonics. However, this augmentation is much accentuated when the generator runs under SD condition. In addition, for this particular fault condition, a clear increase in 
amplitude is also observed for the second harmonic $(+13.5 \mathrm{~dB})$, against the decrease $(-7.9 \mathrm{~dB})$ of the thirdharmonic's amplitude. These experimental results confirm the usefulness of the stray flux for health assessment of the machine circuits.

\section{B. Balanced Resistive Load}

Regardless of fault condition, when the generator supplies balanced resistive load, we see that spectra of output voltage are always characterized by the presence of sidebands $\omega_{1 ; 1}^{ \pm}$. However, we note a moderate reduction in their amplitude ratios. Under FGC, this ratio reaches about $85 \% \mathrm{~K}(3.73 \mathrm{~dB})$ for ID condition (Fig. 10), against $42 \% K(-2.4 \mathrm{~dB})$ under SD condition (Fig. 11). From these experimental results, we can extend the validity of the comparison expression given by (26) to cover the FGC with balanced resistive load.

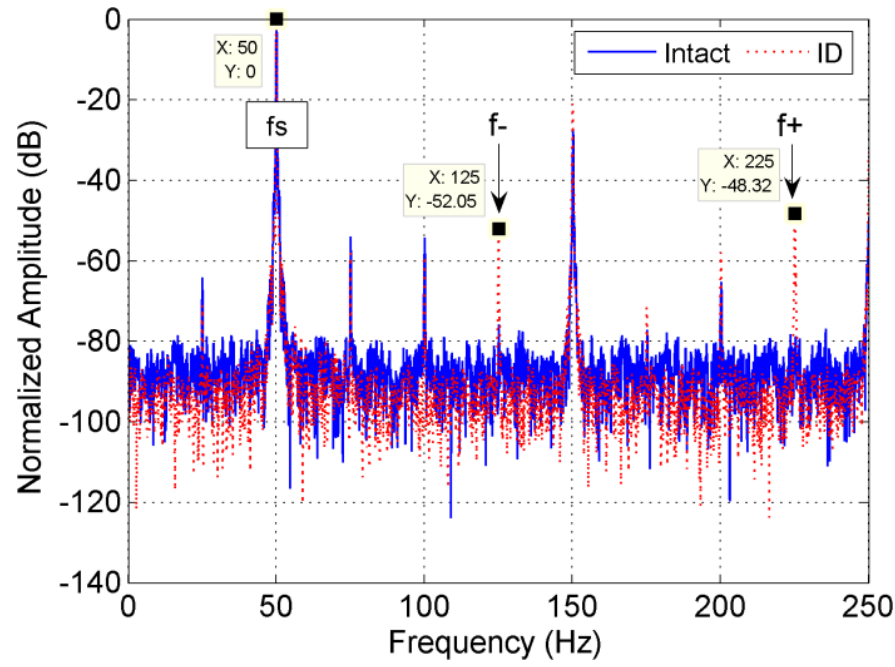

Fig. 10. Output voltage spectra: intact - ID for balanced resistive full-load.

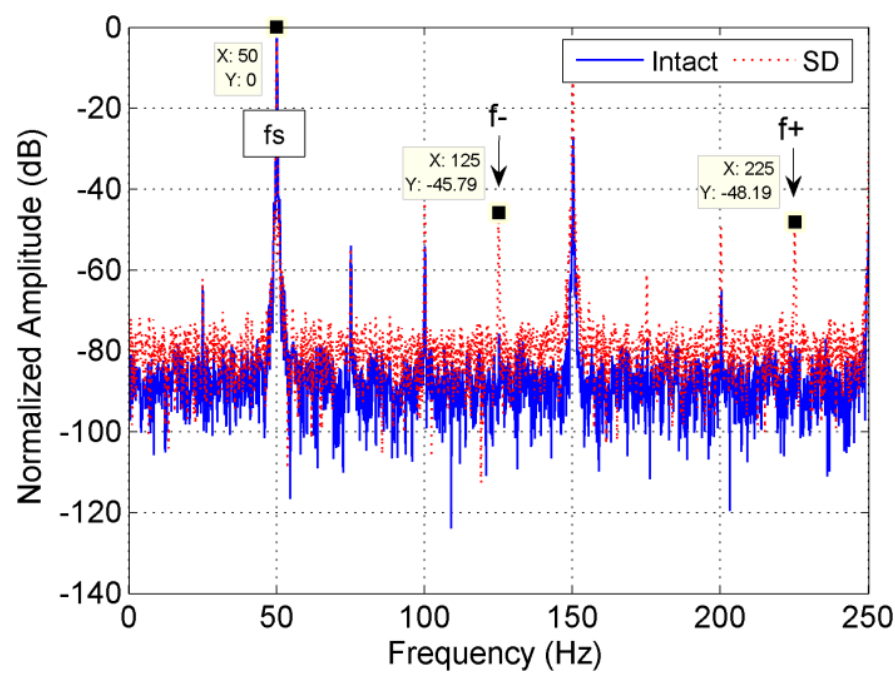

Fig. 11. Output voltage spectra: intact - SD for balanced resistive full-load.

On the other hand, for both diode failure cases, we remark that all characteristic harmonics of stray flux spectra $(\mathrm{H} 4, \mathrm{H} 6$, and H9) that were already observed under UGC are also affected in amplitude. In order not to lose view, we shall merely track solely the behavior of the sixth harmonic. Regardless the fault condition, by loading the generator we note a progressive increase in amplitude for this particular frequency. Under FGC, it reaches about $+5 \mathrm{~dB}$ for the ID condition (Fig. 12), against $+17.9 \mathrm{~dB}$ for the SD condition (Fig. 13).

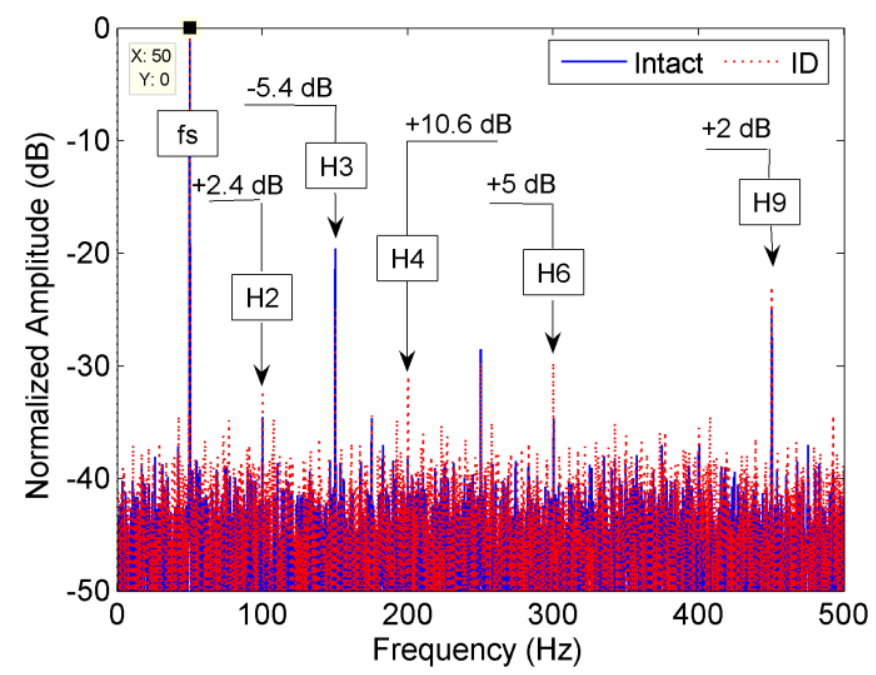

Fig. 12. Stray flux: intact - ID for balanced resistive full-load.

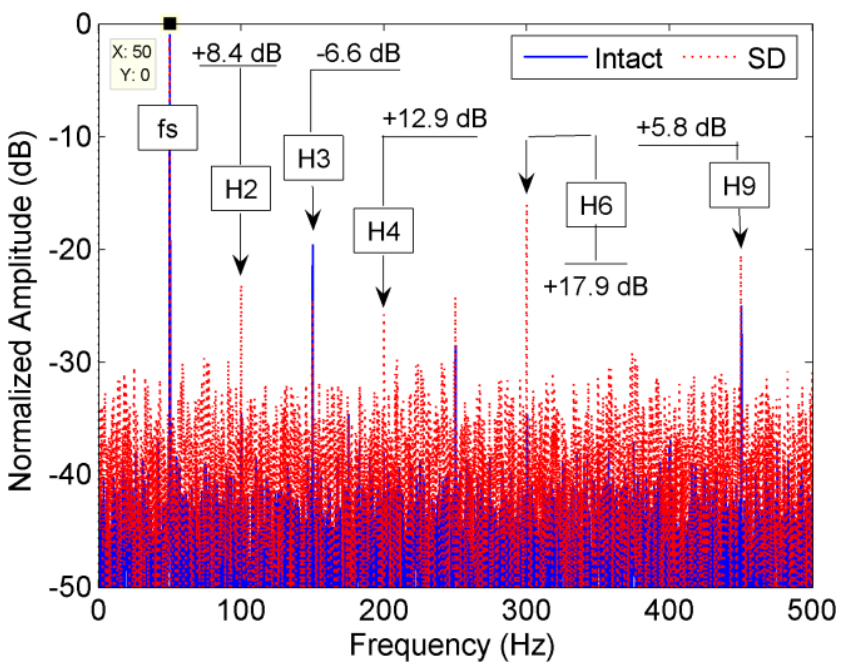

Fig. 13. Stray flux: intact - SD for balanced resistive full-load.

\section{Unbalanced, Lagging, and Non-linear Loads}

Further tests were performed on the generator when it supplies non-ideal loads. Four cases were studied: unbalanced (3\%) resistive load, balanced lagging (0.73) load, unbalanced (3\%) lagging (0.73) load, and non-linear load (six-pulse diodes rectifier).

When the generator runs under ID condition, experimental results have shown that the gradual decrease of the ratio $\xi^{I D}$ by loading effect, remains always respected. Upon reaching the FGC, the minimum value $\left(\xi_{\min }^{I D}=76 \% . K\right)$ is observed for the case of balanced lagging load.

For the cases of resistive load, regardless of balancing state, the downtrend of this ratio has been still observed even for the SD fault condition. The minimum value $\left(\xi_{\min 1}^{S D}=39 \% . K\right)$ was 
observed by reaching the FGC. The clause expected by expression (26) remains always respected.

Rather, in cases of lagging and of non-linear loads the ratio $\xi^{S D}$ has exhibited contrary behavior. Indeed, since we have loaded the generator, this ratio has undergone a sudden leap to reach values greater than $K\left(\xi_{\min 2}^{S D}=115 \% . K\right)$. A progressive increase was then observed. Upon reaching the FGC, the maximum value $\left(\xi_{\max }^{S D}=183 \% . K\right.$ ) was encountered in the case of balanced lagging load. The expression expected by (26) is no longer respected.

Regarding the spectral response of the stray flux, the experimental tests have shown that the amplitude rise of H6 that has characterized the occurrence of diode faults, remains always observed irrespective of the nature and the level of the load. On the other hand, for the cases of resistive and nonlinear loads, the outstanding rise for the H6 amplitude remains specific to the SD condition. However, for the lagging loads this characteristic behavior is no longer guaranteed regardless of the state of load balancing. The $\mathrm{H} 6$ amplitude rise remains moderate as it has been encountered under ID condition.

\section{PRoposed Diagnosis TECHNIQUES}

From previous theoretical predictions and experimental observations, we are going to suggest two diagnosis techniques that may contribute to the state of the art for health assessment of the rotating diodes.

\section{A. Main Output Voltage}

By exploring the output voltage spectral response, we have observed that the occurrence of a diode failure was marked by an amplitude rise of sidebands $\omega_{1 ; 1}^{ \pm}$. Furthermore, regardless of the nature of investigated loads, the ID condition was, exclusively, characterized by belonging of the amplitude ratio to the range delimited by $\xi_{\min }^{I D}=76 \% . K$, and $\xi_{0}^{I D}=100 \% . K$ (Table III).

TABLE III

Ratio $\xi / K(\%)$ for sidebands $\omega_{1,1}^{ \pm}$

\begin{tabular}{lcc}
\hline \hline Generator's load condition & \multicolumn{2}{c}{ Diode failure } \\
\cline { 2 - 3 } & ID & SD \\
\hline No-load & 100 & 53 \\
Balanced resistive load & 85 & 42 \\
Unbalanced (3\%) resistive load & 81 & 39 \\
Balanced lagging (0.73) load & 76 & 183 \\
Unbalanced (3\%) lagging (0.73) load & 90 & 172 \\
Non-linear load (six-pulse diodes rectifier) & 78 & 115 \\
\hline \hline
\end{tabular}

On the basis of above statements, we propose the monitoring algorithm given by Fig. 14 .

Despite the proven efficiency of this algorithm for the detection of diode failures regardless the load nature, its ability to distinguish between conditions of ID and SD cannot be guaranteed for others cases of non-ideal loads that were not studied in this work.

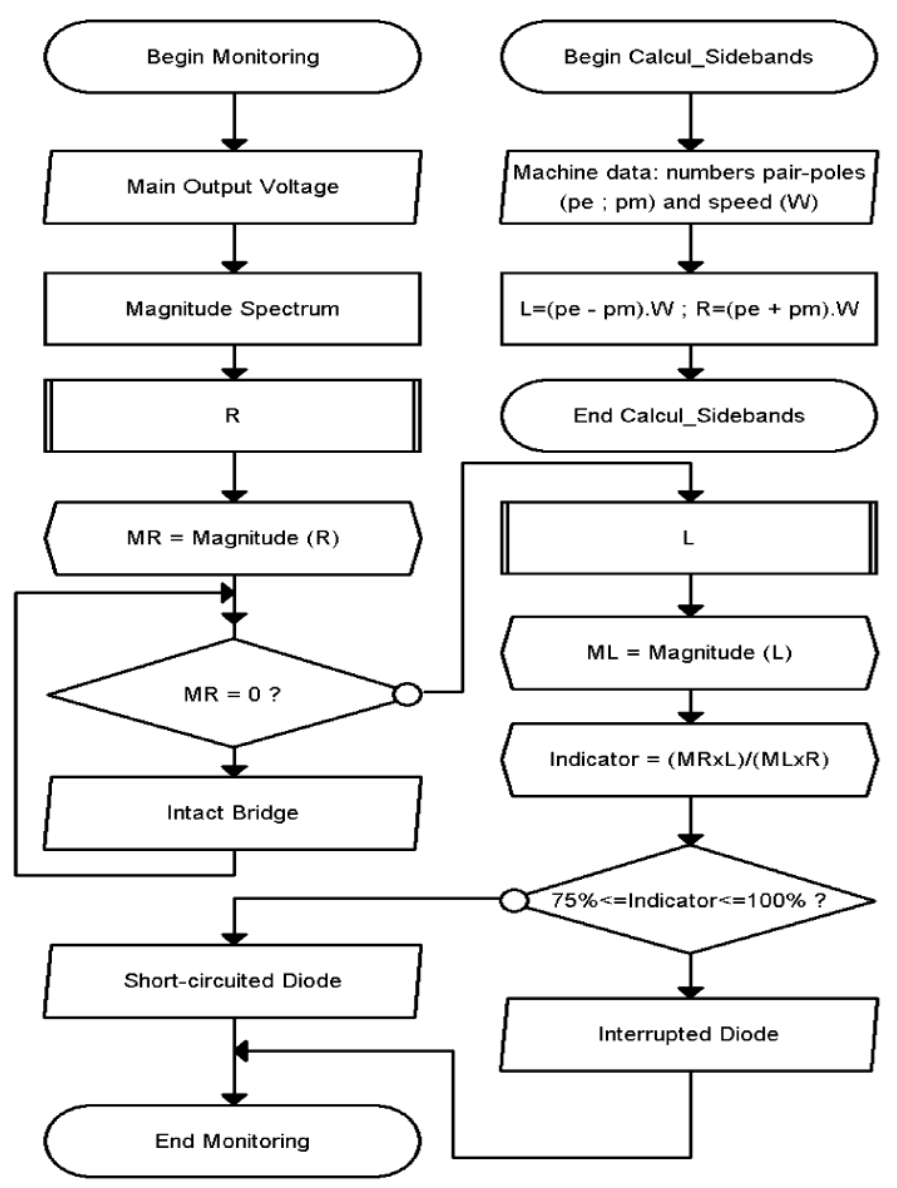

Fig. 14. Monitoring algorithm based on output voltage.

\section{B. Stray Flux}

As mentioned above, the observed rise in amplitude for the sixth harmonic of the stray flux, involves the occurrence of a diode fault. For all load conditions studied, the levels of these increases are reported in Table IV.

\section{TABLE IV}

H6 Amplitude increase (\%) of the stray flux

\begin{tabular}{lcc}
\hline \hline Generator's load condition & \multicolumn{2}{c}{ Diode failure } \\
\cline { 2 - 3 } & ID & SD \\
\hline No-load & 37.40 & 220.26 \\
Balanced resistive load & 77.01 & 688.86 \\
Unbalanced (3\%) resistive load & 72.19 & 194.78 \\
Balanced lagging (0.73) load & 49.97 & 028.38 \\
Unbalanced (3\%) lagging (0.73) load & 42.23 & 064.06 \\
Non-linear load (six-pulse diodes rectifier) & 62.37 & 397.16 \\
\hline \hline
\end{tabular}

By analyzing the variation boundaries of these data, we realize that the ID condition is still characterized by an amplitude augmentation does not exceeding $100 \%$. In contrast, under SD condition, this augmentation is well above (except for lagging loads). Based on these experimental observations, the amplitude monitoring of the six harmonic can be an alternative for diode health assessment. Besides the efficiency of this technique in detecting diode faults, it has the particularity to be efficient for discrimination of the failure nature for resistive loads as well as for the studied non-linear load. However, it cannot be adopted in cases of lagging loads. 


\section{CONCLUSION}

For many load conditions, the proposed algorithm arising from output voltage analysis, has proven ability for distinguishing between two diode failure cases. However, further efforts need to be devoted to explain the behavior of the spectral response when the generator supplies lagging and non-linear loads.

Due to the low cost of the flux sensor, the alternative technique can be an excellent alternative for condition monitoring of rotating diodes. However, its ability to classify the diode fault remains limited to cases of resistive-, and of non-linear loads. In this work, we have limited our analysis to the behavior of the sixth harmonic. To extend the classification ability of this algorithm for covering cases of lagging loads, the exploration of other frequency components, seems to be promising.

\section{REFERENCES}

[1] X. -Y. Li, "A microprocessor-based fault monitor for rotating rectifiers of brushless ac exciters using a pattern-recognition approach," in Proc. 1994 IEEE Instrumentation and Measure. Tech. Conf., pp. 394-397.

[2] M. G. McArdle and D. J. Morrow, "Noninvasive detection of brushless exciter rotating diode failure," IEEE Trans. Energy Conversion, vol. 19, no. 2, pp. 378-383, June 2004.

[3] J. Sottile, F. C. Trutt, and A. W. Leedy, "Condition monitoring of brushless three-phase synchronous generators with stator windings or rotor circuit deterioration," IEEE Trans. Industry Applications, vol. 42, no. 5, pp. 1209-1215, Sept.-Oct. 2006.

[4] T. D. Batzel, D. C. Swanson, and J. F. Defenbaugh, "Predictive diagnostics for the main field winding and rotating rectifier assembly in the brushless synchronous generator," in Proc. 2003 IEEE Symposium on Diagnostics for Electric Machines, Power Electronics and Drives Conf., pp. 349-354.

[5] V. Ruuskanen, M. Niemela, J. Pyrhonen, S. Kanerva, and J. Kaukonen, "Modelling the brushless excitation system for a synchronous machine," IET Electric Power Applications, vol. 3, no. 3, pp. 231-239, May 2009.

[6] K. Veszpremi, I. Schmidt, and M. Hunyar, "Optimal operation of the rotating transformer brushless excitation of synchronous machine," in Proc. 2003 IEEE International Symposium on Industrial Electronics Conf., pp. 627-632.

[7] T. Zouaghi and M. Poloujadoff, "Modeling of polyphase brushless exciter behavior for failing diode operation," IEEE Trans. Energy Conversion, vol. 13, no. 3, pp. 214-220, Sept. 1998.

[8] Y. Li and C. Zhang, "Simulation of harmonic armature reaction in synchronous brushless excitation," in Proc. 2011 Artificial Intelligence, Management Science and Electronic Commerce Conf., pp. 4304-4306.

[9] M. Shahnazari, and A. Vahedi, "Improved dynamic average modelling of brushless excitation system in all rectification modes," IET Electric Power Applications, vol. 4, no. 8, pp. 657-669, Sept. 2010.

[10] S. Feng, X. Jianbo, W. Guoping and X. Yong-hong, "Study of brushless excitation system parameters estimation based on improved genetic algorithm," in Proc. 2008 Electric Utility Deregulation and Restructuring and Power Technologies Conf., pp. 915-919.

[11] W. Na, "A feedforward controller for a brushless excitation system during the diode open circuit fault operation," in Proc. 2011 IEEE Power and Energy Society General Meeting, pp. 1-4.

[12] A. M. Cramer, B. P. Loop, and D. C. Aliprantis, " Synchronous machine model with voltage-behind-reactance formulation of stator and field windings," IEEE Trans. Energy Conversion, vol. 27, no. 2, pp. 391402, June 2012.

[13] M. Salah, K. Bacha, and A. Chaari, "Comparative investigation of diagnosis media for induction machine mechanical unbalance fault," ISA Transactions, vol. 52, no. 6, pp. 888-899, Nov. 2013.

[14] H. Henao, C. Demian, and G.-A. Capolino, "A frequency-domain detection of stator winding faults in induction machines using an external flux sensor," IEEE Trans. Industry Applications, vol. 39, no. 5, pp. 1272-1279, Sept.-Oct. 2003.

\section{BIOGRAPHIES}

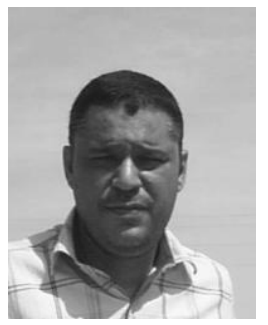

Mohamed Salah was born in El-Guettar, Tunisia, in 1972. He received the B.Sc., and the Aggregation degrees in electrical engineering, from the "Ecole Normale Superieure de l'Enseignement Technique de Tunis (ENSET)" Tunisia, in 1995 and 1996, respectively.

Since 1995, he joined the secondary school Ibn Rached of Gafsa, Tunisia ,as a technical trainer. In 1997 he joined the high institute of technological studies of Gafsa Tunisia, as a technologist then a master technologist (2010).

Since 2004 he is a member of the unit of research in control, monitoring and reliability of the systems at the high school of sciences and techniques of Tunis, Tunisia. His current research interests are fault diagnosis in induction machines and synchronous generators.

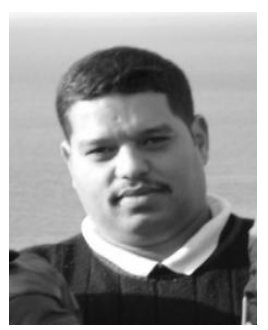

Khmais Bacha was born in Tunis, Tunisia , in 1975. $\mathrm{He}$ received the B.Sc., the M.Sc and the Ph.D. degrees in electrical engineering, from the higher school of sciences and techniques of Tunis, Tunisia, in 1998, 2001 and 2008 respectively and the Habilitation à Diriger des Recherches degree from the higher school of sciences and technology of Tunis, Tunisia in 2013.

Since 2004 he has been an Assistant then an Associate Professor at the Electrical Engineering Department of the national institute of applied sciences and technology (INSAT) of Tunis. His current research interests are fault diagnosis in induction machines and power transformer.

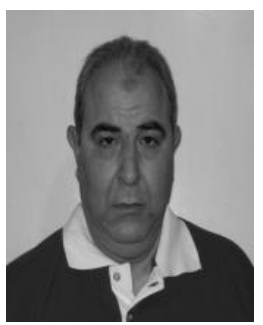

AbdelkaderChaari was born in Sfax, Tunisia, in 1957. He received the the M.Sc. and Ph.D. degrees in electrical engineering from the " Ecole Normale Superieure de l'Enseignement Technique de Tunis (ENSET)" Tunisia , in 1982 and 1986, respectively, and the Habilitation à Diriger des Recherches degree from the higher school of sciences and technology of Tunis, Tunisia in 2008.

Since 1982, he joined the higher school of sciences and techniques of Tunis, Tunisia, (E.S.S.T.T.) as an assistant professor. Currently, he is a director of the research unit : control, monitoring and reliability of the systems (C3S). His main research interests are the identification and control of nonlinear systems, robust estimation and robust filtering.

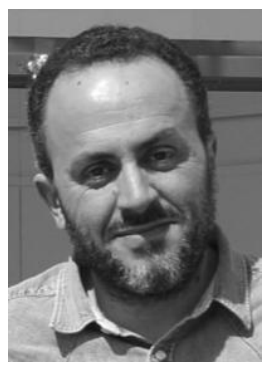

Mohamed El Hachemi Benbouzid was born in Batna, Algeria, in 1968. He received the B.Sc. degree in electrical engineering from the University of Batna, Batna, Algeria, in 1990, the M.Sc. and Ph.D. degrees in electrical and computer engineering from the National Polytechnic Institute of Grenoble, Grenoble, France, in 1991 and 1994 respectively, and the Habilitation à Diriger des Recherches degree from the University of Picardie "Jules Verne," Amiens, France, in 2000.

After receiving the Ph.D. degree, he joined the Professional Institute of Amiens, University of Picardie "Jules Verne," where he was an Associate Professor of electrical and computer engineering. Since September 2004, he has been with the Institut Universitaire de Technologie of Brest, University of Brest, Brest, France, where he is a Professor of electrical engineering. His main research interests and experience include analysis, design, and control of electric machines, variable-speed drives for traction, propulsion, and renewable energy applications, and fault diagnosis of electric machines.

Prof. Benbouzid is an IEEE Senior Member. He is an Associate Editor of the IEEE TRANSACTIONS ON ENERGy CONVERSION, the IEEE TRANSACTIONS ON INDUSTRIAL ELECTRONICS, the IEEE TRANSACTIONS ON SUSTAINABLE ENERGY, and the IEEE TRANSACTIONS ON VeHICULAR TECHNOLOGY. He was an Associate Editor of the IEEE/ASME TRANSACTIONS ON MECHATRONICS from 2006 to 2009 . 